\title{
Eleições e mudança de poder no Rio Grande do Sul: análise nos municípios do estado
}

A relevância da reeleição no o processo eleitoral se dá diante da chance de um governante conduzir bem o seu mandato, visando com isso adquirir maiores chances de continuar no poder e realizar projetos maiores, e que beneficiem um conjunto maior de pessoas. Tendo em vista a importância da temática reeleição, o presente estudo busca analisar o impacto das eleições e mudança de poder nos municípios gaúchos, verificando a alteração das variáveis de desenvolvimento de acordo com a alternância ou não de poder por regiões do estado. A pesquisa se caracteriza como descritiva e quantitativa, e se aproveita de dados eleitorais entre 1992 e 2016 dos municípios gaúchos e relativos às variáveis de desenvolvimento. Percebe-se que o estado apresenta algumas oscilações entre o número de partidos que se mantém no poder, além de que é verificado que as variáveis de desenvolvimento influenciam tanto de forma negativa como de forma positiva. No total houve reeleições em apenas $36,23 \%$ dos casos analisados. É possível notar também que há partidos que se destacam mais em uma região do que outra, e os índices de reeleição acompanham a mesma lógica, pois em algumas regiões há mais reeleições do que em outras. Com isso, é necessário a compreensão dessas diferenças, e que a preferência por um partido é feita devido às ações realizadas na gestão, influenciado por questões históricas, visto que alguns municípios são redutos eleitorais de um ou dois partidos, além do grau de ligação da legenda para com as causas e questões relacionadas à população.

Palavras-chave: Reeleição; Mudança de Poder; Municípios.

\section{Elections and change of power in Rio Grande do Sul: analysis in the municipalities of the state}

\begin{abstract}
The importance of reelection in the electoral process is due to the possibility of a governor to conduct his mandate well, in order to obtain greater chances of remaining in power and carrying out larger projects and benefiting a larger group of people. Considering the importance of reelection, the present study seeks to analyze the impact of the elections and change of power in the municipalities of Rio Grande do Sul, verifying the change of the development variables according to the alternation or not of power by regions of the state. The research is characterized as descriptive and quantitative and takes advantage of electoral data between 1992 and 2016 of the municipalities of Rio Grande do Sul and related to development variables. It can be noticed that the state presents some oscillations between the number of parties that remain in power; besides that, it is verified that the development variables influence both negatively and positively. In total there were reelections in only $36.23 \%$ of the analyzed cases. It is also possible to notice that there are parties that stand out more in one region than another, and the reelection rates follow the same logic, because in some regions there are more reelections than in others. Therefore, it is necessary to understand these differences, and that the preference for a party is made due to the actions carried out in the management, influenced by historical issues, since some municipalities are one or two party constituencies, as well as the degree of caption to the causes and issues related to the population.
\end{abstract}

Keywords: Reelection; Change of Power; Municipalities.

Topic: Gestão Pública

Reviewed anonymously in the process of blind peer.
Received: 05/10/2018

Approved: 11/12/2018
Andressa Petry Müller (iD)

Universidade Federal de Santa Maria, Brasil

http://lattes.cnpq.br/5632200808072041

andressa_miler@hotmail.com

Michel Richard Costa de Quadros (iD)

Universidade Federal do Pampa, Brasil

http://lattes.cnpq.br/2475292158740783

michelrichardcosta_@hotmail.com

Nelson Guilherme Machado Pinto (iD

Universidade Federal de Santa Maria, Brasil

http://lattes.cnpq.br/5647891554789516

http://orcid.org/0000-0003-1105-2271

nelguimachado@hotmail.com

\section{Referencing this:}

MÜLLER, A. P.; QUADROS, M. R. C.; PINTO, N. G. M.. Eleições e mudança de poder no Rio Grande do Sul: análise nos municípios do estado. Revista Brasileira de Administração Científica, v.9, n.3, p.4763, 2018. DOI: http://doi.org/10.6008/CBPC2179-684X.2018.003.0004 


\section{INTRODUÇÃO}

As eleições são de fundamental importância para a sociedade como um todo, contribuindo sobre questões econômicas, sociais, demográficas, políticas, culturais, de desenvolvimento, dentre outros aspectos. Visando isso, seguramente, os candidatos que estão interessados em se eleger tentarão incentivar um maior crescimento econômico próximo ao período eleitoral, de modo que eles possam vir a receber, consequentemente, uma vantagem sobre esse avanço proporcionado.

Segundo Oliveira et al. (2008), existe certo consenso quando se considera que os resultados de uma eleição estão relacionados ao desempenho econômico de um país, raramente o governante empregaria políticas que desagradassem a população durante o período eleitoral, como aumento de impostos ou desvalorização cambial, por exemplo. Dessa maneira, percebe-se que os políticos que possuem convicções distintas, acabam tomando atitudes diferenciadas, a fim de conseguir aumentar as possibilidades de chegar ao poder (ARAÚJO JÚNIOR et al., 2010).

Nesse contexto, observa-se como a população pode ser influenciada, pois muitos não dispõem de conhecimentos específicos, tanto econômicos, quanto políticos, de maneira que interpretam a forma de governo como consideram ser mais adequada. Segundo Cavalcante (2016), existe uma assimetria informacional, onde as consequências da política fiscal adotada em anos eleitorais, como exemplo a redução dos tributos, refletem para uma imagem de gestão eficiente.

Dessa forma, surgem as possibilidades para que um candidato a determinado cargo político consiga chances para reeleição, pois em virtude de ter demonstrado um bom mandato anterior, a população irá acreditar que ele continuará prestando um trabalho adequado, embora, muitas vezes, tenha utilizado recursos inapropriados para garantir a reeleição. Esses mesmos candidatos ainda podem manipular e persuadir os eleitores, criando problemas e depois oferecendo soluções, induzindo comportamentos a população, sendo a mesma muito suscetível a qualquer ação do governo.

Consequentemente há duas visões acerca da reeleição, a primeira, quanto as pessoas que são contra, alegam que pode haver um abuso de poder, pois nessa visão os governantes planejam suas ações somente para permanecer com a autoridade, beneficiando-se de recursos e informações. A segunda, em relação aqueles que são a favor, justificam que apenas um mandato não é suficiente para realizar projetos maiores, além dos eleitores realizarem suas escolhas racionalmente, elegendo o candidato que mostrar mudanças positivas e atitudes que contribuam para a população. Para essas duas visões se dá o nome de ciclo político oportunista e racional, respectivamente (ARAÚJO JÚNIOR et al., 2005; CAVALCANTE, 2016).

Em vista disso, Vasconcelos et al. (2013), ressaltam que existe o estabelecimento de mecanismos de controle, dos quais se espera que além de agirem sobre o endividamento público, também possam vir a ter efeito sobre os possíveis abusos fiscais que estão ligados as eleições. Esses abusos originam os comportamentos intermitentes nas execuções do orçamento público, podendo estar relacionados à prática da reeleição, que ocorre com frequência, prejudicando a rigidez quanto a esse controle imposto. 
Portanto, muito se questiona sobre a mudança de poder, e diferentes são os fatores que estão atrelados a mesma, como a saída da zona de conforto em relação ao governante, a insegurança no período inicial de mandato, a impossibilidade da sequência de projetos, oferecendo tanto vantagens, quanto desvantagens. A cada período eleitoral são apresentados diferentes desejos no que diz respeito aos eleitores, pois os mesmos por vezes esperam reformulações quanto aos governantes, depositando muita expectativa de mudança (IPEA, 2010).

Baseado nisso, o presente estudo busca analisar o impacto das eleições e mudança de poder nos municípios do Rio Grande do Sul, verificando a alteração das variáveis de desenvolvimento conforme as decisões eleitorais e avaliando as diferenças das eleições e mudança de poder por região do estado. Isso porque conforme Barone (2009), nota-se que desde que há eleições de maneira direta, nenhum candidato ao cargo de governador que se candidata à reeleição foi vitorioso no estado do Rio Grande do Sul, e tendo em vista esse fator, é válido vivenciar esse aspecto nos municípios desse estado.

A fim de atingir esses objetivos, o presente artigo está estruturado, além desta introdução, em quatro seções. Na segunda seção é exibido o referencial teórico; na seção seguinte, os procedimentos metodológicos utilizados; na quarta seção são demonstrados os resultados obtidos, e eles são analisados e discutidos e, por fim, são apresentadas as considerações finais do trabalho, além das sugestões para trabalhos futuros.

\section{REVISÃO TEÓRICA}

\section{Administração Eleitoral}

No Brasil, é tarefa simples lançar candidatos e formar um partido. Com base na representação proporcional e do sistema de lista aberta, surgiu o multipartidarismo, assim dispondo com uma quantidade considerável de partidos e candidatos, por consequência aumentando os custos de competição política. Esse resultado se deu pelo fato de o sistema multipartidário oferecer chances para vários partidos políticos, os quais podem se destacar, ou não, e onde o sistema de lista aberta permite a eleição dos candidatos mais votados (MELO et al., 2016).

A fim de reduzir esse problema, a legislação permite que haja a aliança dos partidos, com o propósito de atingir sucesso. Essa associação de partidos ocorre em duas etapas, onde na primeira há o intuito de fortalecer o desempenho da candidatura, a fim de recompensas, como votos ou cargos. Já na segunda etapa há o interesse da coalizão governamental, onde as alianças que são feitas geram um benefício, pois há o amparo de vários partidos (LIMONGI et al., 2008; FREITAS, 2016; MELO et al., 2016).

Entretanto, para que os partidos continuem exercendo os benefícios que lhe são proporcionados, é necessário que eles estejam aptos para se renovar, e, portanto, consigam sempre reaparecer por diversos períodos eleitorais. Sendo assim, eles não devem somente atender as demandas que lhes são exigidas, mas devem ter a incumbência de empregar técnicas eficientes para destacar-se no cenário eleitoral, possibilitando sua continuidade (PERES et al., 2017). 
Em decorrência a isto, os partidos proporcionam um serviço público de grande relevância, como selecionar, recrutar e capacitar candidatos capazes para que possam exercer cargos públicos, estimulando os eleitores e envolvendo-se com as eleições, independente do resultado. Tudo isso é expresso por meios de comunicação social, e cada partido tem diferente acesso às mídias, como televisão, rádio e imprensa, embora o preceito a todos seja o mesmo, ter igualdade e direito à informação (ZOVATTO, 2005).

Ainda na percepção de Zovatto (2005) tanto o partido deve apresentar os candidatos, quanto os eleitores devem conhecer os mesmos, para que assim possa ter uma eleição mais informada e democrática. Em vista disso, o autor ainda aborda que há o surgimento dos financiamentos para as campanhas eleitorais, onde se coletam os recursos necessários para o período eleitoral, a fim de informar da maneira mais adequada os eleitores.

Segundo o Tribunal Superior Eleitoral (2018), o processo eleitoral no Brasil, é elaborado pela Justiça Eleitoral, e adequa-se para as escolhas municipais, estaduais e federal, onde em nível federal há o amparo do Tribunal Superior Eleitoral, e o Tribunal Regional Eleitoral, conjuntamente a juízes e juntas eleitorais em cada estado e no Distrito Federal. A disputa eleitoral nas cidades onde a população é inferior a 200 mil pessoas aptas a votar, é definida em um turno e pelo sistema de maioria simples, onde se faz presente o maior número integral de votos. Já nas cidades com número superior a 200 mil eleitores, há a probabilidade de ser realizada disputa em segundo turno, quando nenhum dos candidatos receber mais de $50 \%$ dos votos (NICOLAU, 2012).

Também segundo a Lei no 9.504, de 30 de setembro de 1997, Art. 1ํ, as eleições para cargos políticos em âmbito municipal, estadual e federal são disputadas no primeiro domingo do mês de outubro do ano correspondente, a ser realizado em todo o país. Já no Art. 2ㅇ § 1으, se tratando em segundo turno, onde nenhum candidato alcance a maioria absoluta dos votos, a eleição será realizada no último domingo de outubro, onde concorrem somente os dois candidatos mais votados, considerando eleito o qual receba o maior número dos votos válidos (BRASIL, 2012).

Dessa forma, a votação no país se dá de forma democrática, onde se escolhem os candidatos a partir de eleições livres, tendo a participação dos partidos políticos mais influentes e dos indivíduos que compõe a sociedade, a vista de eleger a pessoa mais qualificada ao cargo. Portanto, os sistemas eleitoral e partidário são significantes para a execução da atuação política democrática. Em decorrência a isso, há a intenção de um governante se manter no poder, embora haja um número limitado de mandatos para o mesmo, ocorrendo a tentativa de conseguir se reeleger e conseguir o apoio da população para isso (ARAUJO JUNIOR, et al., 2005; MENEGUIN et al., 2005; ÁLVARES, 2014).

\section{Votação e Reeleição}

No Brasil, segundo a Constituição Federal (1988), a idade mínima para ser candidato aos cargos eletivos varia de acordo com o cargo pretendido: dezoito anos para vereador, vinte e um anos para deputado federal, deputado estadual ou distrital, prefeito, vice-prefeito; trinta anos para governador e vice-governador de estado e do Distrito Federal; e trinta e cinco anos para presidente da república, vice-presidente e senador. 
Além disso, a mesma CF (1988) estipula o período do mandato: oito anos para senadores da República, e quatro anos para os demais.

Segundo Braga et al. (2016), o processo eleitoral e sua competição é o cerne da democracia moderna, sendo que os cidadãos vão às urnas de tempos em tempos para escolher seus representantes. Ao fim, há a existência de dois grupos, os vencedores e os vencidos. A ideia que cerca um Estado democrático é a de que os grupos vencidos aceitem seu revés e respeitem as regras do jogo, na esperança de que possam sair vencedores em outra oportunidade (BRAGA et al., 2016).

A reeleição para os cargos do Executivo (prefeitos, governadores e presidente da República) trata-se de um fenômeno recente na democracia brasileira, sendo que a mesma passou a vigorar somente em 1997, com a Emenda Constitucional no 16 (CAVALCANTE, 2015); e o então presidente Fernando Henrique Cardoso foi o primeiro presidente a se utilizar dessa norma quando em 1998 foi candidato à reeleição e saiu vencedor do pleito presidencial. Além disso, segundo Silva et al. (2013), naquele pleito se observou um alto índice de reeleição também em âmbito estadual.

Segundo Braga et al. (2013), após a redemocratização do país e a possibilidade de reeleição para os cargos do Executivo, a identificação dos fatores que influenciam nas chances de reeleição tem sido alvo de muitas discussões no Brasil. Ademais, desde o advento da Emenda que permitiu a reeleição, predomina também o debate na opinião pública em relação à manutenção ou extinção da reeleição, embora na maioria das vezes sem uma fundamentação baseada em dados (CAVALCANTE, 2016).

Os contrários à reeleição defendem que ela gera personalismo no poder, riscos de perpetuação, além de ações de abuso de poder. Na outra via, os favoráveis argumentam que a reeleição acaba valorizando a experiência administrativa, e visto que um mandato é um período muito curto para realizar grandes projetos de governo, a reeleição inibe a descontinuidade de políticas públicas efetivas e populares (CAVALCANTE, 2016). Segundo Borba et al. (2017), a reeleição trouxe a possibilidade de um mandato de oito anos, com um processo de avaliação da gestão no meio do período; caso a avaliação seja positiva, o governante fica (reelege-se), caso seja negativa, a possibilidade de um opositor sair vencedor do pleito cresce.

Com a instituição da reeleição, para Borba et al. (2017) é possível propor uma tipologia dos candidatos a cargos de executivo: candidatos à reeleição titulares; candidatos à reeleição substitutos, governistas, e por fim os oposicionistas. A primeira categoria engloba os candidatos que foram eleitos pelo voto popular, e disputam a reeleição para o segundo mandato. Já o segundo grupo é formado pelos candidatos que geram o cargo com o mandato em andamento, e se candidatam à reeleição (seja por afastamento coercitivo do titular, seja por iniciativa do titular por motivos de doença, por exemplo). Os governistas são aqueles que possuem o apoio do atual chefe de executivo, ou com o apoio do partido do mandatário. Por fim, os oposicionistas são os candidatos que buscam se eleger sem o apoio do atual chefe do executivo (BORBA et al., 2017).

Em termos municipais, a reeleição é um tema relevante, ao passo de que a análise entre a gestão fiscal e a dinâmica do processo político se mostra um objeto de estudo fértil, em especial devido ao amplo processo de descentralização pós-Constituição de 1988, no qual os municípios ganharam mais protagonismo 
tanto em relação às suas receitas e despesas, como também em relação às responsabilidades (CAVALCANTE, 2016). Nessa dinâmica de reeleição a nível municipal, o alinhamento com o governador do respectivo estado possui influência positiva na possibilidade de manutenção do cargo de prefeito. Em seus estudos, Cavalcante (2015) corroborou com o senso comum de que ter o apoio ou ser do mesmo partido do governador traz consigo um aspecto positivo, não apenas para facilitar a administração municipal, como também em uma eventual tentativa de reeleição.

Em relação ao mandato político, Cavalcante (2016) afirma que um esforço maior do prefeito em primeiro mandato (visando a reeleição, por vezes) pode ser alcançado durante a segunda gestão, visto que o know-how e experiência adquiridos no mandato anterior podem ser suficientes para tal. Além disso, para permanecer no ambiente político, é necessário passar pelo crivo do voto, e em um período anterior a esse, indicação do partido. Em caso de revés, devem procurar novos "postos de trabalho", seja através das nomeações, seja esperando a próxima oportunidade nas eleições (BARRETO, 2017).

Segundo Castro et al. (2014) as regras eleitorais brasileiras dificultam a formação de identidades partidárias estáveis, sendo que neste caso é comum o voto "personalista", direcionado no candidato popular, ou até mesmo indicado por chefes políticos locais, amigos ou colegas de trabalho, sem considerar, ou até mesmo desconhecer, o partido ao qual pertence. Em meio a esse voto mais "personalista" é que se insere a propaganda política, enquanto estratégia de consolidação de ações, além de marketing político (SILVA, 2012).

Diante disto, uma campanha eleitoral visa obter a vitória nas eleições, marcar espaço político, além de buscar representatividade (ESTRADA et al., 2013). Destarte, em meio à campanha política se insere a participação dos recursos financeiros, sendo que segundo Heiler et al. (2016), há a necessidade por parte dos candidatos a maiores volumes de recursos, além da exigência por partes dos mesmos em articularem o elemento financeiro às formas de comunicação, visando atingir e convencer o maior número de eleitores

É possível afirmar que o eleitor brasileiro premia políticos com bons desempenhos fiscais e que prezam pela transparência, da mesma forma que agem com caráter de sanção para os que arrecadam impostos e não aplicam à contrapartida em serviços básicos para a população (CAVALCANTE, 2016). Além disso, o eleitor se importa, segundo Cavalcante (2015) com a capacidade do gestor público em gerar os benefícios esperados, e em caso de bons resultados na economia, ocorrem acréscimos nas chances dos políticos de situação, no processo eleitoral. Saliente-se que no Brasil diferente do contexto encontrado em países desenvolvidos, a ideologia de governo no poder não tem relação direta com a cobrança de impostos sobre a propriedade particular (AVELLANEDA et al., 2017).

Além disso, para Silva et al. (2013), é consenso que os resultados de uma eleição estão atrelados ao desempenho econômico do ente federativo (município, estado, país), e que dificilmente um governante aplicará políticas e medidas que vão contra os interesses da sociedade durante o período eleitoral. Estudos sugerem, também, que o eleitorado adota uma postura punitiva em relação aos políticos que aumentam despesas, em especial nos períodos precedentes ao pleito (CAVALCANTE, 2016). 
Segundo Braga et al. (2016), posições ideológicas extremas influenciam o efeito negativo da derrota e da consequente desaprovação do mandato político, além de afetar negativamente a satisfação com o processo democrático em vigência. O processo de reeleição no Brasil é motivo de muitos debates, mas sem a menor dúvida que o processo eleitoral se tornou o principal mecanismo de accountability, ora utilizado pelos eleitores para premiar bons gestores, ora para punir os atuais ocupantes dos cargos devido às suas políticas e práticas na gestão (CAVALCANTE, 2016).

\section{Aspectos de desenvolvimento e contexto eleitoral}

As eleições são de fundamental importância para o desenvolvimento de um país, pois é nesse momento em que a população faz suas escolhas, a fim de eleger os candidatos mais capacitados para promover o progresso e o crescimento do município, estado ou a nível federal. Assim, os eleitores vão absorvendo as informações que lhes são transmitidas, onde a mesma forma, permanece ou muda de opinião à medida que a comunicação sobre os candidatos varia (LIMEIRA et al., 2010).

A população deve estar ciente do significado de democracia, do voto consciente e o exercício dele, a fim disso é necessária uma educação para que os eleitores consigam realizar um processo eleitoral justo. Também no âmbito da educação, percebe-se o quanto há a preocupação com a qualidade da educação oferecida no país, dessa forma os eleitores escolherão seu candidato a partir do resultado que conseguirem observar, quanto as qualificações que as escolas possuem, bem como a forma de ensino que a mesma oferece (OLIVEIRA, 2012; FIRPO et al., 2017).

Consequentemente, identifica-se que o único modo de obter satisfação ou correções no desempenho escolar é por meio das eleições. Muitas vezes a melhora dos índices educacionais se deve ao fato de haver estratégias políticas, onde na primeira percepção há uma melhora, mas com o passar do tempo há regressões (FIRPO et al., 2017; PINO, 2017).

Em decorrência a isto, é necessário que exista um controle dos gastos públicos, havendo um equilíbrio entre as receitas e despesas, onde são criadas regras, propostas e leis para que ocorra um monitoramento das contas sob o mandato atual. Para impedir que se tenha um agravamento da situação orçamentária no mandato seguinte ao mesmo que está em atividade, existem contenções de gastos a aquele incumbido ao cargo, principalmente em anos eleitorais (ARAÚJO et al., 2015).

Portanto, para conseguir alcançar esses objetivos, foi criada a Lei de Responsabilidade Fiscal (LRF), a qual foi elaborada como um programa de estabilização fiscal, baseada nos conceitos de organização, administração e responsabilidade. Logo é possível compreender que há outros meios de obter receitas além da arrecadação de tributos e subsídios sociais e econômicos, sendo preceito que os mesmos devem ser utilizados para garantir os direitos a população, como investimentos na saúde, educação, assistencialismo, entre outros (DANTAS et al., 2014; ARAÚJO et al., 2015).

Percebe-se que quando se trata de investimentos na saúde, há prejuízos quando ocorrem mudanças de partidos nos mandatos, pois eles possuem ideias e princípios diferentes ao partido que está no poder. Os 
conflitos entre partidos, bem como suas rivalidades estabelecem qual sentido a saúde irá tomar, deixando vestígios na política de estado, sendo o mesmo limitado aos interesses privados (CBES, 2012).

Assim, ainda de acordo com o Centro Brasileiro de Estudos de Saúde (CBES, 2012), há a tentativa de mercantilizar aquilo que é um direito a todos, em face a uma concepção sintetizada de governabilidade, onde não vigoram os interesses em comum. E como instrumento de tais negociações estão as secretarias municipais de saúde, percebendo-se a vulnerabilidade e a falsa promessa do governante com a saúde.

Identifica-se, ainda, que se os partidos que estão com autoridade, e desejarem se manter no poder devem estar atentos a economia, pois ela é um princípio de relevância sob os resultados das eleições. Há a compreensão de que os agentes econômicos podem modificar aspectos da economia a fim de que se prejudique candidatos, embora se considere o fato de que quem decide as eleições é a população, e somente eles podem ter controle quanto a isso (BORSANI, 2003).

Além disso, segundo Borsani (2003), as atividades que os governos realizam, atingem os resultados econômicos, influenciando sob incumbências produtivas, taxa de inflação e grau de empregabilidade. Da mesma forma, a condição da economia influencia na renda e nas oportunidades de trabalho para a população, intervindo nas decisões eleitorais de forma positiva ou negativa (BORSANI, 2003).

Dessa forma, percebe-se que há uma baixa participação das mulheres na representação eleitoral, não havendo muito espaço para elas, devido ao comportamento de muitos anos somente os homens se candidatarem (SACCHET et al., 2012). Portanto, é notório também que fatores de propriedade socioeconômicos e demográficos podem também intervir no controle fiscal (CAVALCANTE, 2016).

\section{METODOLOGIA}

A pesquisa é caracterizada como descritiva e quantitativa. Isso porque as informações coletadas são abordadas de forma estatística e o fornecimento de dados ocorre de forma mais precisa. De acordo com Hair et al. (2005), esses dados são obtidos através de várias escalas numéricas. A partir disso foi realizado um estudo nos municípios gaúchos na faixa temporal que contempla as eleições de 1992 a 2016.

Em um primeiro momento foram analisadas as estatísticas descritivas das reeleições por meio da análise descritiva nos anos de eleições, nas regiões e referente aos partidos. Posteriormente, foi realizado uma análise de regressão de dados em painel, conforme o modelo abaixo:

$$
y=\alpha+\beta 1 \text { educa }+\beta 2 \text { finan }+\beta 3 \text { econo }+\beta 4 \text { demog }+\beta 5 \text { saude }+\mu
$$

em que:

y é a ocorrência reeleição no município; educa é a variável de educação representada pelos os concluintes do ensino médio no município; finan é a variável de finanças públicas que são as despesas municipais no município; econo é a variável econômica de produto interno bruto no município; demog é a variável demográfica de número de eleitores no município; saúde é a variável de saúde representada pela taxa de mortalidade no município; $\alpha$ efeito individual específico; $\beta$ é coeficiente angular de relação das variáveis da regressão; e $\mu$ é o termo de erro aleatório. 
É válido destacar que o modelo de painel desse estudo contempla apenas o período de 2004 a 2016, período sobre o qual foi permitido a reeleição para cargos do executivo e que todos os municípios do estado passaram a existir até os dias de hoje. Assim, o painel desse estudo contempla três períodos de análise (2004/2008, 2008/2012 e 2012/2016) para os 496 municípios gaúchos.

Dessa forma, conforme modelo de estudo é utilizado dados em painel, visto que há uma combinação das tipologias de série temporal e corte transversal. A tipologia de dados em painel consiste em observações de $n$ entidades ou objetos de análise para dois ou mais períodos, combinando as dimensões de séries temporais e corte transversal. Além disso, uma das vantagens na utilização de dados em painel consiste em proporcionar mais eficiência e graus de liberdade para análise, captando aspectos que não são visualizados quando é feita outro tipo de análise (GREENE, 2008).

Quanto à característica dos dados, o modelo de painel apresentado nesse estudo é do tipo balanceado, ou seja, os dados estão disponíveis para todas as unidades de corte transversal em todos os períodos (GREENE, 2008). A partir disso foi possível verificar a estimação do modelo por um método de estimação em painel. Os mais utilizados são os de Efeitos Fixos (EF) e de Efeitos Aleatórios (EA). Assim, o modelo de EF considera o fato de que pode haver correlações entre o intercepto e as variáveis explicativas em qualquer período. Já o modelo de EA possui as mesmas suposições do modelo de EF, variando apenas no tratamento do intercepto, que passa a ser tratado como variável aleatória e não mais como um parâmetro fixo (BALTAGI, 2005; GREENE, 2008). Entretanto, as utilizações desses modelos acabam tornando-se excludentes e, conforme a características dos dados, um modelo terá sua utilização mais recomendada.

Portanto, uma forma de decidir entre qual modelo utilizar é a comparação dos efeitos dos métodos, verificando se existe correlação entre os fatores não observados e as variáveis explicativas a partir da aplicação do teste de Hausman. Este teste tem como hipótese nula testar se a diferença entre os coeficientes dos EF e EA não é sistemática. Além disso, o método de EA acaba consumindo muitos graus de liberdade, existindo a necessidade de haver número de períodos superiores ao número de coeficientes da regressão e, quando não é possível fazer a estimação por meio desse empecilho, deve-se utilizar EF (GREENE, 2008). Como o número de variáveis independentes (cinco) é maior que o período de análise (três), utilizou-se no trabalho EF.

A fim de verificar alguns aspectos e pressupostos dos modelos regressivos para não gerar resultados enviesados, foram realizados alguns testes econométricos. Para verificar a presença de heterocedasticidade, ou seja, se os termos de erro possuem variâncias divergentes, foi realizado o teste de Wald. A verificação se os erros são aleatórios ou não correlacionados, isto é, se há de presença de auto correlação, foi realizado o teste de Cumby-Huizinga.

O universo de estudo ficou limitado aos municípios do Rio Grande do Sul, o qual possui ao todo 496 municípios, sendo considerados todos eles para a análise, que de parte descritiva contemplou 1992 a 2016 e que na parte do painel contemplou o período de 2004 a 2012. Os dados utilizados nessa pesquisa foram coletados no Tribunal Regional Eleitoral do Rio Grande do Sul para coletar os dados de eleições e para os 
dados socioeconômicos dos municípios a bases utilizadas foram a da Fundação de Economia e Estatística (FEE) do Rio Grande do Sul.

\section{RESULTADOS E DISCUSSÃO}

\section{Análise descritiva das eleições municipais (1992-2016)}

Em relação à reeleição por período eleitoral, percebe-se que na Tabela 1 é possível fazer uma análise dela baseando-se em seis períodos. É válido destacar que no total houve reeleições em apenas 36,23\% dos casos analisados para todos os casos analisados durante todo o período. A ideia de considerar o número de reeleições por período exige uma análise que deve levar em conta o fato de que municípios foram criados nesse meio tempo, de maneira que em 1996 houveram de fato 426 municípios com pleitos eleitorais capazes de reeleger o partido; outros 70 municípios tiveram em 1996 sua primeira eleição, portanto sem chances de reeleição. Ainda em 1996, ocorreram 316 resultados contrários à reeleição, o que corresponde à 74,18\% dos pleitos, sendo que apenas 110, ou seja, em 25,82\% dos casos ocorreu a situação da reeleição.

Em 2000, eram 466 os municípios com condições de reeleição, sendo que os outros 30 municípios tiveram seu primeiro pleito nessa ocasião. É válido ressaltar que essa foi a última eleição que apresentou essa situação. Em relação ao pleito anterior, o número de reeleições saltou de 110 para 204, subiu de 25,82\% em 1996 para 43,78\% em 2000. Já o número de casos onde o partido que comandava não logrou êxito em sua tentativa de reeleição caiu, se comparado ao período anterior: 316 em 1996 e 262 casos em 2000.

Tabela 1: Reeleições por período eleitoral.

\begin{tabular}{lccc}
\hline Período & No de reeleições & Não-reeleições & Munícipios não existiam no período \\
\hline $1992 / 96$ & 110 & 316 & 70 \\
$1996 / 00$ & 204 & 262 & 30 \\
$2000 / 04$ & 208 & 288 & 0 \\
$2004 / 08$ & 234 & 262 & 0 \\
$2008 / 12$ & 220 & 276 & 0 \\
$2012 / 16$ & 176 & 320 & 0 \\
\hline
\end{tabular}

Fonte: Portal TRE-RS (Tribunal Regional Eleitoral)

No que tange ao pleito de 2004, visto que a população dos municípios era de 496 já, foi possível perceber acréscimos tanto no número de reeleições, como no caso de não-reeleições. Em relação ao anterior, houve um acréscimo de 4 casos nos êxitos, e 26 casos acrescidos nos casos negativos; respectivamente $41,94 \%$ de casos com êxitos e 58,06\% sem sucesso. Em 2008, o percentual de casos que lograram sucesso foi de 47,18\% (234 casos), enquanto os casos sem êxito chegaram à 262, aproximadamente 52,82\%. Saliente-se que este foi o período que apresentou uma situação de maior equilíbrio, na série estudada.

Em 2012, o número de casos nos quais o partido que estava no poder conseguiu a reeleição reduziuse, quando comparado ao pleito anterior. De 234 em 2008 para 220 casos (44,35\% do total); enquanto o número de casos sem êxito subiu de 262 para 276 casos; aproximadamente 55,65\% do número de municípios. Por fim, no último pleito municipal analisado, o número de reeleições reduziu-se novamente, 35,48\% dos casos apenas, o equivalente à 176 casos; enquanto o número de casos onde a reeleição não se 
concretizou ocorreu em 320 municípios. Com isso, saliente-se que esse pleito foi o que apresentou o maior número de casos de insucesso de reeleições. Segundo Cavalcante (2015), o número de partidos envolvidos no pleito é um dos fatores que influencia nas chances de reeleição; quanto maior o número de partidos, menores serão as chances.

Para uma maior riqueza na discussão adotou-se a divisão dos municípios em macrorregiões. Os municípios foram divididos em 3 macrorregiões: Nordeste com 158 municípios, Norte com 221 municípios e Sul com 117 municípios. Em 1996, dos 110 casos de êxito na reeleição, 51,82\% ocorreram na macrorregião Norte; 57 casos. Além disso, a macrorregião Sul, que possui menos municípios foi a que apresentou o menor número de casos, 23 apenas.

Em 2000, os casos de êxito apresentaram aumento nas três regiões, sendo que na macrorregião Nordeste ocorreu o maior crescimento, cerca de 45 casos a mais. Porém, da mesma forma que no pleito anterior, a região com o maior número de reeleições foi a Norte, com 79 casos. No pleito de 2004, à exceção do Norte, as duas demais regiões apresentaram quedas no número de casos com sucesso; foram 95 casos ( $45,67 \%$ do total) de sucesso na Norte, 70 casos no Nordeste (33,65\%); e os demais $20,68 \%$ concentraram-se nos 43 casos do Sul.

Tabela 2: Reeleições por período eleitoral nas mesorregiões.

\begin{tabular}{cccc}
\hline Período & Macrorregião Nordeste & Macrorregião Norte & Macrorregião Sul \\
\hline $1992 / 96$ & 30 & 57 & 23 \\
$1996 / 00$ & 75 & 79 & 50 \\
$2000 / 04$ & 70 & 95 & 43 \\
$2004 / 08$ & 71 & 107 & 56 \\
$2008 / 12$ & 73 & 90 & 57 \\
$2012 / 16$ & 54 & 89 & 33 \\
\hline Total & 373 & 517 & 262 \\
\hline
\end{tabular}

Fonte: Portal TRE-RS (Tribunal Regional Eleitoral)

Em 2008, pleito no qual o número de sucessos na reeleição obteve aumentos se comparado à 2004, nas regiões houve aumentos também. Porém, seguindo a tendência já conhecida, o Norte apresentou o maior percentual dentre os 234 êxitos: foram 107 casos, aproximadamente 45,73\%. Na região Nordeste verificou-se $30,34 \%$; 71 casos, e no Sul os $23,93 \%$ restantes, nos 56 casos.

No pleito seguinte, ocorreu o inverso de 2004: as regiões Nordeste e Sul apresentaram aumento no número de casos, dois e um caso a mais; respectivamente, enquanto a Norte apresentou queda de 17 casos. Ainda assim, verificou-se o maior percentual na Norte, 40,91\% (90 casos); e o menor na Sul, 57 casos e $25,91 \%$.

No último pleito analisado, 2016, a tendência de queda nas reeleições verificada a nível geral atingiu as três regiões, ainda assim a região com a maior concentração de reeleição foi a Norte, com 89 casos, equivalente a $50,57 \%$ do total. Destaque-se que dentre os pleitos analisados este foi o qual a região Sul apresentou o menor percentual: os 33 casos representaram 18,75\%.

Até mesmo devido ao fato de ser a região com a maior concentração de municípios, a Norte apresentou o maior somatório de reeleições no período, 517 casos de êxito. Em segundo apareceu o Nordeste, com 373 casos, sendo que a Sul; com a menor gama de municípios, manteve o terceiro posto. 
Cavalcante (2016) afirma a necessidade de se considerar o patrimônio político conquistado no pleito anterior, isto é, apoios advindos de um alinhamento com o Executivo Estadual e Federal contribuem para uma melhor percepção perante o eleitorado.

Tabela 3: Partidos X Reeleições, por pleito eleitoral.

\begin{tabular}{cccccccc} 
Partido & $\mathbf{1 9 9 2 / 9 6}$ & $\mathbf{1 9 9 6 / 0 0}$ & $\mathbf{2 0 0 0 / 0 4}$ & $\mathbf{2 0 0 4 / 0 8}$ & $\mathbf{2 0 0 8 / 1 2}$ & $\mathbf{2 0 1 2 / 1 6}$ & Total \\
$\mathbf{1 0}$ & 35 & 74 & 62 & 76 & 67 & 70 & 374 \\
$\mathbf{1}$ & 50 & 67 & 64 & 67 & 30 & 52 & 370 \\
$\mathbf{7}$ & 18 & 25 & 39 & 37 & 30 & 23 & 172 \\
$\mathbf{8}$ & 2 & 12 & 18 & 26 & 28 & 16 & 102 \\
$\mathbf{2}$ & 2 & 13 & 9 & 15 & 8 & 8 & 55 \\
$\mathbf{1 1}$ & 0 & 5 & 7 & 4 & 6 & 5 & 27 \\
$\mathbf{3}$ & 3 & 6 & 3 & 3 & 5 & 3 & 23 \\
$\mathbf{9}$ & 0 & 2 & 4 & 4 & 4 & 8 & 22 \\
$\mathbf{6}$ & 0 & 0 & 0 & 1 & 0 & 0 & 3 \\
$\mathbf{4}$ & 0 & 0 & 2 & 0 & 0 & 0 & 2 \\
$\mathbf{5}$ & 0 & 0 & 0 & 1 & 1 & & 0 \\
\hline
\end{tabular}

Fonte: Portal TRE-RS (Tribunal Regional Eleitoral)

Analisando a tabela 3, em relação aos partidos que obtiveram mais casos de reeleições, o partido 10 apresentou o melhor desempenho, tendo alcançando 374 reeleições. Por sua vez, o partido 1 obteve um desempenho um pouco inferior, 370 casos. Ressalte-se que apenas 11 siglas conquistaram reeleições nesse período, e destas quatro delas conquistaram mais que 100 reeleições. Saliente-se que dos 1152 casos de reeleição admitidos no total de todos os pleitos analisados, $88,37 \%$ concentrou-se apenas no somatório destes 4 partidos, que conquistaram 1018 casos.

A tabela 4 apresenta os casos de reeleição na macrorregião Nordeste, sendo que os partidos 4 e 5 não obtiveram nenhum êxito nas reeleições, dentre os 6 pleitos analisados. Segundo mais vitorioso no que tange ao número de reeleições dentre os municípios, o partido 1 destacou-se em primeiro nos 6 pleitos, sendo seguido pela legenda 10. E assim como no quadro geral, as legendas 7 e 8 destacaram-se também. Além disso, percebe-se que das três reeleições conquistadas no estado, a legenda 6 conquistou 2 na macrorregião Nordeste.

Tabela 4: Reeleições na Macrorregião Nordeste, por partido e pleito eleitoral.

\begin{tabular}{|c|c|c|c|c|c|c|c|}
\hline M1 & $1992 / 96$ & $1996 / 00$ & $2000 / 04$ & $2004 / 08$ & 2008/12 & $2012 / 16$ & Total \\
\hline 1 & 18 & 27 & 26 & 32 & 30 & 19 & 152 \\
\hline 10 & 6 & 25 & 19 & 15 & 19 & 14 & 98 \\
\hline 7 & 3 & 7 & 9 & 7 & 7 & 5 & 38 \\
\hline 8 & 1 & 6 & 5 & 7 & 7 & 6 & 32 \\
\hline 2 & 2 & 4 & 6 & 7 & 3 & 3 & 25 \\
\hline 11 & 0 & 3 & 2 & 1 & 2 & 4 & 12 \\
\hline 3 & 0 & 2 & 2 & 1 & 1 & 1 & 7 \\
\hline 9 & 0 & 1 & 1 & 0 & 3 & 2 & 7 \\
\hline 6 & 0 & 0 & 0 & 1 & 1 & 0 & 2 \\
\hline 4 & 0 & 0 & 0 & 0 & 0 & 0 & 0 \\
\hline 5 & 0 & 0 & 0 & 0 & 0 & 0 & 0 \\
\hline Total & 30 & 75 & 70 & 71 & 73 & 54 & 373 \\
\hline
\end{tabular}

Fonte: Portal TRE-RS (Tribunal Regional Eleitoral)

A tabela 5 retrata a situação na macrorregião Norte, sendo que a legenda 10 conquistou o maior número de reeleições, 189 casos, seguida da legenda 1, que obteve 144 êxitos. Semelhante à tabela anterior, percebe-se que o terceiro e o quarto partido mais significativo foram 7 e 8 , com 94 e 48 casos; 
respectivamente. Além disso, percebe-se que $64,4 \%$ dos casos de reeleição foram obtidos pelas legendas 10 e 1; 333 casos dos 517 totais. Ademais, a legenda 6 conquistou 1 reeleição nessa região, dentre as 3 conquistadas no estado durante os pleitos analisados no estudo.

Tabela 5: Reeleições na Macrorregião Norte, por partido e pleito eleitoral.

\begin{tabular}{|c|c|c|c|c|c|c|c|}
\hline M2 & $1992 / 96$ & $1996 / 00$ & $2000 / 04$ & $2004 / 08$ & $2008 / 12$ & $2012 / 16$ & Total \\
\hline 10 & 24 & 33 & 29 & 41 & 30 & 32 & 189 \\
\hline 1 & 20 & 25 & 22 & 23 & 27 & 27 & 144 \\
\hline 7 & 10 & 8 & 24 & 22 & 15 & 15 & 94 \\
\hline 8 & 1 & 6 & 11 & 12 & 12 & 6 & 48 \\
\hline 2 & 0 & 4 & 3 & 6 & 3 & 3 & 19 \\
\hline 9 & 0 & 1 & 2 & 2 & 0 & 4 & 9 \\
\hline 3 & 2 & 1 & 0 & 1 & 2 & 1 & 7 \\
\hline 11 & 0 & 1 & 2 & 0 & 1 & 0 & 4 \\
\hline 4 & 0 & 0 & 2 & 0 & 0 & 0 & 2 \\
\hline 6 & 0 & 0 & 0 & 0 & 0 & 1 & 1 \\
\hline 5 & 0 & 0 & 0 & 0 & 0 & 0 & 0 \\
\hline Total & 57 & 79 & 95 & 107 & 90 & 89 & 517 \\
\hline
\end{tabular}

Fonte: Portal TRE-RS (Tribunal Regional Eleitoral)

A região Sul, sendo a que possui o menor número de municípios, acabou reproduzindo o cenário já visto nas outras duas regiões: legendas 10 e 1 (respectivamente) nas primeiras posições em relação aos maiores casos de reeleições. Além disso, as legendas 7 e 8 apresentaram destaque, 40 e 22 casos e reeleições, respectivamente. Destarte, o partido 5 conquistou suas duas reeleições nessa região.

Tabela 6: Reeleições na Macrorregião Sul, por partido e pleito eleitoral.

\begin{tabular}{|c|c|c|c|c|c|c|c|}
\hline M3 & $1992 / 96$ & $1996 / 00$ & $2000 / 04$ & $2004 / 08$ & $2008 / 12$ & $2012 / 16$ & Total \\
\hline 10 & 5 & 16 & 14 & 21 & 17 & 14 & 87 \\
\hline 1 & 12 & 15 & 16 & 12 & 13 & 6 & 74 \\
\hline 7 & 5 & 10 & 6 & 8 & 8 & 3 & 40 \\
\hline 8 & 0 & 0 & 2 & 7 & 9 & 4 & 22 \\
\hline 2 & 0 & 5 & 0 & 2 & 2 & 2 & 11 \\
\hline 11 & 0 & 1 & 3 & 3 & 3 & 1 & 11 \\
\hline 3 & 1 & 3 & 1 & 1 & 2 & 1 & 9 \\
\hline 9 & 0 & 0 & 1 & 2 & 1 & 2 & 6 \\
\hline 5 & 0 & 0 & 0 & 1 & 1 & 0 & 2 \\
\hline 4 & 0 & 0 & 0 & 0 & 0 & 0 & 0 \\
\hline 6 & 0 & 0 & 0 & 0 & 0 & 0 & 0 \\
\hline Total & 23 & 50 & 43 & 57 & 56 & 33 & 262 \\
\hline
\end{tabular}

Fonte: Portal TRE-RS (Tribunal Regional Eleitoral)

Apesar de um prefeito, ao fim do seu segundo mandato, estar impossibilitado de ser candidato, segundo Cavalcante (2016), o esforço por uma boa gestão e na construção de uma boa imagem parte da preocupação com a continuidade do seu partido no poder, com isso evitando decisões que venham a desgastar sua imagem. Saliente-se que com o amadurecimento do sistema democrático brasileiro, ocorrem ajustes entre as demandas dos eleitores e as propostas e planos de governo elaborados por candidatos aos cargos, em especial do executivo.

\section{Análise das questões de desenvolvimento atreladas a reeleição}

A partir da Tabela 7, é possível perceber as diferentes relações entre a reeleição com as variáveis de desenvolvimento. 
Tabela 7: Resultados da estimação da regressão do modelo de estudo pelo método de Efeitos Fixos por meio de Erros Padrão Robusto (VCE) com variável dependente reeleição.

\begin{tabular}{llc}
\hline Variável & Coeficiente & Significância \\
\hline Const & $-0,251129$ & $0,0037^{* * *}$ \\
Educa & $-4,89091$ & $0,0250^{* *}$ \\
Finan & 3,38895 & $0,0115^{* *}$ \\
Econo & 1,22016 & $0,0432^{* *}$ \\
demog & 1,19892 & $0,0368^{* *}$ \\
saude & $-0,0205625$ & $0,0024^{* * *}$ \\
\hline
\end{tabular}

Nota: Valores com dois asteriscos $\left({ }^{* *}\right)$ denotam coeficientes significativos ao nível de $5 \%$ e com três asteriscos $\left({ }^{* * *}\right)$ denotam coeficientes significativos ao nível de $1 \%$.

Percebe-se, ao analisar as variáveis de desenvolvimento, que a educação tem um impacto negativo sobre a reeleição, bem como a saúde, que demonstra a mesma influência desfavorável. As taxas relacionadas ao ensino no Rio Grande do Sul são relativamente baixas, demonstrando a falta de interesse no aprendizado, e tal educação, segundo a lei no 9.394, art. 2o, é um dever da família e do estado, orientada na liberdade e na solidariedade, tendo como propósito o progresso do aluno, bem como sua capacitação para o desempenho como cidadão e para o trabalho (BRASIL, 1996). É importante ressaltar ainda que, segundo Morin (2014), o saber também abrange o risco de ilusão e equívoco, portanto, mesmo a pessoa sendo instruída, ela está sujeita a errar.

Aos aspectos relacionados a saúde, verifica-se que ela é influenciada por questões sociais, econômicas e ambientais, sendo ela um elemento importante para as metas de uma sociedade. É necessário dispor de igualdade na saúde, sendo fundamental a criação e a conservação de um contexto que abrange socialmente a formação de políticas, garantindo a proteção dos direitos humanos (CARVALHO, 2013; SILVA, 2015).

Já ao investigar os aspectos econômicos, financeiros e demográficos, é possível perceber que eles possuem influência positiva sobre a reeleição. Quando se trata de questões econômicas e financeiras, para Rennó et al. (2006), as mesmas aparecem em debates sobre a influência da economia nas eleições, analisando que se a economia for bem, o governo consegue se manter no poder, já se as taxas de inflação forem altas, bem como tenha aumento de desemprego, e baixo valor salarial, as chances do governo se manter no poder são menores, havendo decréscimo de popularidade do mesmo.

Verifica-se também que se a resposta do mercado financeiro for pública, ela é utilizada por candidatos, podendo intervir sobre as intenções de voto. Além disso, os eleitores podem não avaliar o governo apenas economicamente, mas são capazes de levar em conta as perspectivas de campanha do candidato, admitindo as complicações econômicas, em prol de prováveis compensações (RENNÓ et al., 2006).

E, quando analisados os aspectos demográficos, é possível notar a influência que municípios novos tem sobre a reeleição, pois nessas localidades, os candidatos tem mais propensão de se reeleger, e muito se explica pelo disponível que pode ser gasto, o mesmo não possui obrigações atrasadas, podendo investir com pessoal e infraestrutura melhores para sua administração. Além desses fatores, é explícito como a região sul 
pune o mau desempenho do governo, influenciando sobre sua reeleição, e isso se deve a extensão sul ser mais desenvolvida (MENDES et al., 2004).

\section{CONSIDERAÇÕES FINAIS}

Com a possibilidade de reeleição para os cargos de executivo, essa temática tem sido um campo muito estudado e questionado ao longo dos anos. Além disso, a reeleição mostra-se um fator importante para os gestores e para a população com um todo, visto que possibilita a ênfase em projetos desenvolvimentistas, com isso trazendo benefício a todos.

Destarte, saliente-se a existência de consequências desfavoráveis decorrentes da reeleição, como governantes que se valem da situação e acabam promovendo uma gestão sem comprometimento, visando apenas seu benefício e não atendendo às demandas da população. Com isso, esse governante cria falsas promessas aos eleitores, fazendo com que eles acreditem, e como consequência ele consiga se reeleger.

Dessa forma, é imprescindível realizar investigações no âmbito da reeleição, para perceber quais são realmente os índices de reeleição de um partido, analisando períodos distintos. Com isso, no presente estudo foi efetuado uma pesquisa no estado do Rio Grande do Sul, e foi possível perceber que, ao longo do tempo, a quantidade de partidos reeleitos oscilou.

Nota-se que no período de 2000, houve um aumento nos partidos reeleitos, sendo superior em 43,78\%, com 94 casos a mais de reeleição, se comparado ao período anterior. À vista disso é possível identificar que a partir do período de 2012, se iniciou uma queda no número de reeleitos, reduzindo-se à um índice de 14 partidos que não se reelegeram, e em 2016, 44 partidos não reeleitos, representando uma queda acentuada nos últimos anos de eleição.

Também foi avaliado o índice de reeleição por mesorregiões do estado, assim, percebe-se que o maior número de reeleitos é na região norte, onde apenas a partir de 2012 registrou-se o início de queda. Na região nordeste ocorreram variações nos anos, coexistindo aumentos e quedas nos índices de reeleição. Já a região sul apresentou os menores índices de reeleição, onde não houve aumentos significativos. Por fim, foi possível notar que nas três regiões houve uma queda na reeleição dos partidos em 2016.

Ainda, quando avaliados os partidos que obtiveram maiores casos de reeleição, o partido 10 apresentou 374 reeleições, obtendo a maior representação. Já os partidos que obtiveram menor índice de reeleição foram os partidos 4 e 5 , com apenas 2 reeleições cada.

Quando analisadas as reeleições nas mesorregiões, na região nordeste, o partido que mais se reelegeu no decorrer dos anos foi o partido 1, com 152 reeleições, e o partido com menor índice foram os partidos 4 e 5, com nenhuma reeleição cada. Na região norte, o partido que obteve mais reeleições foi o 10, com 189 reeleições ao longo do período analisado, e o que apresentou menor índice foi o 5, com nenhuma reeleição. E na região Sul o partido que mais apresentou reeleições foi o 10, assim como na região norte, mas com um índice menor, com apenas 87 reeleições, e o menor índice apresentado foram dos partidos 4 e 6 , com nenhuma reeleição cada. 
Portanto, é possível notar as variações nos índices de reeleição nas regiões analisadas, onde essa oscilação, se deve, em grande parte, as variáveis de desenvolvimento, sendo elas: educação, saúde, demográficas, econômicas e financeiras. Foi possível identificar que elas influenciam de formas positivas e negativas a reeleição, sendo que as variáveis de educação e saúde impactam de forma negativa, e as variáveis demográficas, econômicas e financeiras levam a impactos positivos a reeleição.

Como sugestão para futuros estudos, sugere-se a ampliação dos municípios analisados, para outros estados e até mesmo no Brasil todo, visando assim verificar o impacto em outras realidades, não apenas no estado supracitado. Além disso, estudos a nível de governadores dos estados também trariam um panorama dinâmico e interessante à discussão da temática reeleição no contexto eleitoral brasileiro.

\section{REFERÊNCIAS}

ÁLVARES, M. L. M.. Entre eleitoras e elegíveis: as mulheres e a formação do eleitorado na democracia brasileira: quem vota? quem se candidata?. Cadernos Pagu, Campinas, n.43, p.119-167, 2014.

ARAUJO, A. H. S.; FILHO, J. E. S.; GOMES, F. G.. Lei de responsabilidade fiscal: efeitos e consequências sobre os municípios alagoanos no período 2000-10. Revista de Administração Pública: RAP, Rio de Janeiro, v.49, n.3, p.739759, 2015

ARAUJO JUNIOR, A. F.; CANÇADO, P.; SHIKIDA, C. D.. Economics and politics: $O$ que determina as chances de reeleição em municípios?: O caso das eleições municipais de minas gerais- 2000. Informe GEPEC, Toledo, v.9, n.2, 2005.

AVELLANEDA, C. N.; GOMES, R. C.. Mayoral quality and municipal performance in Brazilian local governments. Revista O \& S, v.24, n.83, p.555-579, 2017.

BALTAGI, B. H.. Econometric Analysis of Panel Data. 3 ed. England: John Wiley \& Sons, 2005.

BARONE, L. S.. Responsabilização política nos estados brasileiros: o voto econômico nas eleições para governador. Dissertação (Mestrado em Administração Pública) Fundação Getúlio Vargas, São Paulo, 2009.

BARRETO, A. A. B.. Para onde ir? A trajetória eleitoral dos prefeitos das capitais estaduais brasileiras (1996-2014) Opinião Pública, v.23, n.1, p.194-229, 2017.

BORSANI, H.. Eleições e economia: instituições políticas e resultados macroeconômicos na américa latina (1979-1998). Belo Horizonte: UFMG, 2003.

BORVA, F.; CERVI, E. U.. Relação entre propaganda, dinheiro e avaliação de governo no desempenho de candidatos em eleições majoritárias no Brasil. Opinião Pública, v.23, n.3, p.754-785, 2017.

BRASIL. Decreto no 7.791, de 17 de agosto de 2012 Regulamenta a lei no 9.504, de 30 de setembro de 1997, que estabelece normas para as eleições. Brasília: DOU, 2012.

BRASIL. Lei no 9.394, de 20 de dezembro de 1996.

Estabelece as diretrizes e bases da educação nacional.
Brasília: DOU, 1996.

BRAGA, M. S. S.; CASALECCHI, G. A.. Vencedores e perdedores nas eleições presidenciais de 2014: o efeito da derrota nas urnas sobre a satisfação e o apoio em relação à democracia no Brasil. Opinião Pública, v.22, n.3, p.550-568, 2016.

CARVALHO, A. I.. Determinantes sociais, econômicos e ambientais da saúde. Rio de Janeiro: Saúde Brasil 2030, 2013.

CARVALHO, F. A. A.; OLIVEIRA, K. V.. A contabilidade governamental e a teoria dos ciclos políticos: Uma análise empírica fiscal e contábil sobre os municípios do estado do rio de janeiro - 1998 / 2006. Revista de Educação e Pesquisa em Contabilidade, Brasília, v.3, n.1, p.46-64, 2009.

CASTRO, M. M. M.; NUNES, F.. Candidatos corruptos são punidos?: Accountability na eleição brasileira de 2006. Opinião Pública, v.20, n.1, p.26-48, 2014.

CAVALCANTE, P.. Desempenho fiscal e eleições no Brasil: uma análise comparada dos governos municipais. Revista de Administração Pública, v.50, n.2, p.307-330, 2016.

CAVALCANTE, P.. Vale a pena ser um bom prefeito?: Comportamento eleitoral e reeleição no Brasil. Opinião Pública, v.21, n.1, p.87-104, 2015.

CEBS. Centro Brasileiro de Estudos De Saúde. Radicalizar a democracia para garantir o interesse público na saúde: O CEBES nas eleições municipais de 2012. Saúde em Debate, Rio de Janeiro, v.36, n.93, p.309-313, 2012.

DANTAS, F. P. F.; SILVA, M. R. F.. Os direitos sociais no brasil: abordagem sobre sua violação e proposições para concretização. Revista constituição e garantia de direitos, Natal, v.7, n.1, p.1-26, 2014.

ESTRADA, R. J. S.; BRITO, L. C.; VERARDI, M.; ALMEIDA, A. L. N.. Participação política: fundamentos, planejamento, execução e coordenação de campanha eleitoral. Revista de Ciências da Administração, v.15, n.35, p.23-35, 2013. 
FIRPO, S.; PIERI, R.; SOUZA, A. P.. Electoral impacts of uncovering public school quality. EconomiA, Amsterdam, v.18, n.1, p.1-17, 2017.

FREITAS, V. E. V. S.. Alianças partidárias nos estados brasileiros: Das coligações às coalizões de governo (19862010). In: ENCONTRO DA ASSOCIAÇÃO BRASILEIRA DE CIÊNCIA POLÍTICA, 10. Anais. 2016.

GREENE, W. H.. Econometric analysis. 6 ed. New Jersey: Prentice Hall, 2008.

HAIR, J.; BABIN, B.; MONEY, A.; SAMOUEL, P.. Fundamentos de métodos de pesquisa em administração. Bookman, 2005.

HEILER, J. G.; VIANA, J. P. S. L.; SANTOS, R. D.. O custo da política subnacional: a forma como o dinheiro é gasto importa?: Relação entre receita, despesas e sucesso eleitoral. Opinião Pública, v.22, n.1, p.56-92, 2016.

IPEA. Instituto de Pesquisa Econômica Aplicada. Brasil em desenvolvimento 2010: estado, planejamento e políticas públicas. 2 ed. Brasília: IPEA, 2010.

LIMEIRA, T. M. V.; MAIA, T.. Comunicação política e decisão de voto: $O$ que as pesquisas revelam. Ponto e vírgula, Limeira, n.8, p.42-55, 2010.

LIMONGI, F.; MESQUITA, L.. Estratégia partidária e preferência dos eleitores: As eleições municipais em São Paulo entre 1985 e 2004. Novos Estudos - CEBRAP, São Paulo, n.81, p.46-67, 2008.

MELLO, C. A. V.; SOARES, K. C. C.. Coligações partidárias em eleições proporcionais municipais: Fragmentação e sucesso de candidatos com baixa densidade eleitoral. Análise Social, Lisboa, v.51, n.220, p.684-719, 2016.

MENDES, M.; ROCHA, C. A. A.. O que reelege um prefeito?. Brasília: Consultoria Legislativa do Senado Federal, 2004.

MENEGUIM, F. B.; BUGARIN, M. S.; CARVALHO, A. X.. Texto para discussão $n$ - 1135: $O$ que leva um governante à reeleição?. Brasília: IPEA, 2005.

MORIN, E.. Os sete saberes necessários à educação do futuro. Brasília: Cortez, 2014.

NICOLAU, J.. Sistemas Eleitorais. Rio de Janeiro: FGV, 2012.
OLIVEIRA, D. C.. Justiça eleitoral e educação para a cidadania. Brasília: TSE, 2012.

PERES, P.; MACHADO, A.. Uma tipologia do recrutamento partidário. Opinião Pública, Campinas, v.23, n.1, p.126-167, 2017.

PINO, I. R.. Crise do projeto democrático de educação. Saúde \& Educação, Campinas, v.38, n.140, p.531-535, 2017.

RENNÓ, L.; SPANAKOS, A. P.. Fundamentos da Economia, Mercado Financeiro e Intenção de Voto: As Eleições Presidenciais Brasileiras de 1994, 1998 e 2002. Revista de Ciências Sociais, Rio de Janeiro, v.49, n.1, p.11-40, 2006.

SACCHET, T.; SPECK, B. W.. Financiamento eleitoral, representação política e gênero: uma análise das eleições de 2006. Opinião Pública, Campinas, v.18, n.1, p.177-197, 2012.

SILVA, F. F.; BRAGA, M. J.. Determinantes da reeleição municipal da Bahia para o período de 2000 a 2008. Revista Planejamento e Políticas Públicas, n.40, p.257- 276, 2013.

SILVA, M. G.. Sustentabilidade socioambiental e a retórica neodesenvolvimentista: apontamentos sobre meio ambiente e saúde no Brasil. Serviço Social \& Sociedade, São Paulo, n.123, p.428-446, 2015.

SILVA, S. C.. Marketing político e comportamento eleitoral: reflexões sobre as estratégias de marketing político em campanhas eleitorais. Revista Brasileira de Marketing, v.11, n.1, p.113-136, 2012.

TRE. Tribunal Regional Eleitoral. Resultado das eleições. Porto Alegre: TRE, 2018.

TRE. Tribunal Regional Eleitoral. Processo eleitoral. Porto Alegre: TRE, 2018.

VASCONCELOS, R. D.; FERREIRA JÚNIOR, S.; NOGUEIRA JUNIOR, R. P.. A dinâmica da execução orçamentária federal do brasil sob a ótica dos ciclos políticos eleitorais, 19852010. Economia Aplicada, Ribeirão Preto, v.17, n.3, p.325354, 2013.

ZOVATTO, D.. Financiamento dos partidos e campanhas eleitorais na américa latina: uma análise comparada. Opinião Pública, Campinas, v.11, n.2, p.287-336, 2005.

A CBPC - Companhia Brasileira de Produção Científica (CNPJ: 11.221.422/0001-03) detém os direitos materiais desta publicação. Os direitos referem-se à publicação do trabalho em qualquer parte do mundo, incluindo os direitos às renovações, expansões e disseminações da contribuição, bem como outros direitos subsidiários. Todos os trabalhos publicados eletronicamente poderão posteriormente ser publicados em coletâneas impressas sob coordenação da Sustenere Publishing, da Companhia Brasileira de Produção Científica e seus parceiros autorizados. Os (as) autores (as) preservam os direitos autorais, mas não têm permissão para a publicação da contribuição em outro meio, impresso ou digital, em português ou em tradução. 